\title{
The relationship between burnout and job satisfaction among psychiatric nurses
}

\author{
Sahar Behilak ${ }^{1,2}$, Ayat Saif-elyazal Abdelraof*3 \\ ${ }^{1}$ Psychiatric and Mental Health Nursing, Mansoura University, Egypt \\ ${ }^{2}$ Faculty of Applied Medical Science, Yanbu, Taibah University, Saudi Arabia \\ ${ }^{3}$ Psychiatric and Mental Health Nursing, Tanta University, Egypt
}

Received: July 12, 2019

DOI: $10.5430 /$ jnep.v10n3p8
Accepted: October 11, 2019

Online Published: November 17, 2019

\begin{abstract}
Objective: One of the core concerns in psychiatric nursing is job burnout among nurses, because burnout had harmful impacts on both nurses' health and their ability to cope with job demands. Moreover, long term job stress can cause burn out and reduce their level of satisfaction. Aim: The aim of the study was to explore the relationship between burnout aand job satisfactions among psychiatric nurses.

Methods: Descriptive correlation design was utilized. The study was conducted at Psychiatric Department in Tanta University Hospital and Tanta Mental Health Hospital. The study sample consisted of 50 staff nurses. Tools were utilized for collection of data: First, the Burnout Inventory by Maslach; Second, the Job Satisfaction scale. It measured the general job satisfaction of the nursing staff. This scale has five domains: Personal factors, Work organization, Content and amount of work, Working unit and Leadership.

Results: It was found that the majority of nurses had job dissatisfaction. In relation to staff nurses' burnout, staff nurses' job burnout and its components were found. It was observed that the majority of nurses had high burnout. Regarding burnout components, specifically, in relation to emotional exhaustion, it was found that the majority of nurses experienced high emotional exhaustion and depersonalization compared low accomplishment. It was found that there was significant negative correlation between burnout and job satisfaction, the highest frequency of nurses had high burnout and had low level of job satisfaction.

Conclusions: The highest frequency of nurses had high burnout and had low level of job satisfaction. It recommended newly developed interventions to alleviate nurses' burnout and increase job satisfaction, thereby enhancing the quality of healthcare. So, further support of managers in the prevention of burnout is a necessity. Thus, it will enhance creativity, job satisfaction, self-worthiness, and service quality.
\end{abstract}

Key Words: Burnout, Nurses, Job satisfaction

\section{INTRODUCTION}

Over the last decades, burnout and job satisfaction were highly significant in the psychiatric nursing. Burnout is a psychological issue that appears in difficult personal relations as segment of their work environment, such as nursing professionals. ${ }^{[1]}$ Nurses, in general, and especially psychi- atric nurses are generally considered as a high risk group for burnout as they are in continuous working interaction and interpersonal contact with psychiatric patients and their families. ${ }^{[2]}$

Burnout is a physical, mental, and emotional reaction to

\footnotetext{
${ }^{*}$ Correspondence: Ayat Saif-elyazal Abdelraof; Email: saif_ayat@yahoo.com; Address: Psychiatric and Mental Health Nursing, Tanta University, Egypt. 
continuous high stress and ineffective coping methods. ${ }^{[3]}$ It is a syndrome characterized by emotional exhaustion, depersonalization, and reduced personal accomplishment. ${ }^{[4]}$ Emotional exhaustion is feeling of emotionally overwhelmed by relation with other people. Depersonalization is unfeeling and callous reaction toward the recipients of one's service or care. Decrease of personal accomplishment is a lack of feelings of competence and successful work accomplishment. ${ }^{[5]}$

Freudenberger (1974) ${ }^{[6]}$ utilized the 'burnout' for the first time to explain the boredom and loss of physical and emotional motivation among workers. Maslach et al. (2001) ${ }^{[7]}$ outlined burnout as 'a long response to continuous emotional and interpersonal stressors in the work'. In nursing profession, factors like occupational stressors and low satisfaction about the workplace environment usually operate as crucial elements for burnout. Burnout has psychological, physiological and behavioral components. Poor working conditions such as an workload, incompatible work demands, role ambiguity, administration conflicts and traumatic experience like dealing with death, shifting between different, handling uncooperative patients, supportive relations in the work, providing quality nursing care to clients and low control is a significant related to burnout symptoms. ${ }^{[8-10]}$

Numerous variables have been related to burnout in psychiatric nursing. These components incorporate: work fulfillment, accessibility ofsocial support, aspects of good care (such as one's caseload, sort of patients, and aggression at the work-location), a few components of the work environment (such as staffing, move work, salary, and over obligations), and the level of burnout. Nurses' burnout comes about in mental and fatigue, headache, sleep disturbances and low quality of patient care, work turnover, absenteeism and over duties. Other components that increment burnout levels are educational level, night shifts, stress levels, destitute adapting styles, job dissatisfaction environment, nurture inability, and work related pressure. ${ }^{[11,12]}$

Efficiency of an organization based on the worth of their workers. Job satisfaction and job performance are positively interconnected. Health professionals are at high risk of experiencing burnout syndrome and by turn, their motivation declines. The presence of burnout and low job satisfaction among health professionals might be a negative issue to patients care. Because burned out and occupationally dissatisfied nurses usually have low work motivation and they deliver subclinical. As a conclusion, health professionals like nurses are at high risk for burnout and job dissatisfaction. ${ }^{[13]}$

Stressful hospital working environments are associated with nursing burnout. Psychiatric nurses are vulnerable to burnout and the patients are more developing poor care out-

Published by Sciedu Press comes. ${ }^{[14,15]}$ Psychiatric nurses have a higher vulnerability to burnout syndrome and low job satisfaction. Factors like 'Working with psychiatric patient', 'generally unsupportive workplace atmosphere', 'lack of respect from others', 'low self-esteem, role conflicts', 'place of job', 'having less time' for 'unstructured working rules and responsibilities' make psychiatric nurses more vulnerable to burnout and demotivation syndrome. ${ }^{[16]}$

Job satisfaction is a major discrepancy between what an individual expects from a job and how much a person actually have. ${ }^{[17]}$ If these expectations were met, they become satisfied; if not met, they become dissatisfied. ${ }^{[18]}$ Job satisfaction is person liking or disliking his job. Various factors influence job satisfaction level; these factors are including payment and benefits, organizational fairness promotion system, quality of working environment to leadership system and social relationship. ${ }^{[19,20]}$

Therefore, low job satisfaction among nurses and positive outcome such as a low patient fall rate influence quality other than cost of patient care. Poor patient care outcome such as an increased frequency of patient fall rate will increases healthcare cost. Moreover, poor patient outcomes increase the length of stay, increase resource utilization, and increase the cost of treatment. Nurses who were not satisfied at work were also found to distance themselves from their patients and their nursing profession. ${ }^{[21]}$

Consequently, satisfied nurses are more productive, committed and will providing higher quality patient care. However, there are times when nurses find themselves in "Burnout" situations manifested by emotional exhaustion, detachment, and lack enthusiasm to work and achieve. Additionally, nursing burnout has a negative effect on the patient health care and patient satisfaction. Burnout and low Job satisfaction contributes into the nurses' job quality and care given. ${ }^{[22]}$

\subsection{Study aim}

To study the relationship between burnout and job satisfaction among psychiatric nurses.

\subsection{Research questions}

(1) What is the burnout level among psychiatric nurses?

(2) What is the job satisfaction level among psychiatric nurses?

(3) What is relation between burnout and job satisfaction among psychiatric nurses?

\section{MATERIALS AND METHOD}

\subsection{Research design}

A descriptive correlation design was used. 


\subsection{Setting}

Tanta Mental Health Hospital and psychiatric department at Tanta university hospital, Egypt. Tanta Mental Health Hospital is under the supervision and direction of ministry of health with a capacity of 80 beds and provides health care services to Gharabya, Menofia and Kafrelsheikh governorates population.

\subsection{Subjects}

The study sample included all nurses working in Tanta Mental Health Hospital and psychiatric department at Tanta university hospital. They have diploma, technical nursing institute, and bachelor degree and have nursing practice for at least 1 year. After excluding those who did not match our criteria, 50 nurses were invited to participate in the study. The sample will be calculated according to the (Epi-Info software).

\subsection{Tools}

Tool I: The study subjects were asked to fill in the predesigned self-administered questionnaire sheet which included the following items:

A-Socio-demographic and general characteristics of studied nurses, e.g.

- Age, gender.

- Social status, residence.

- Education, years of experience in the clinical field,

- Working department, number of working hours per week.

- Number of working shifts per month

- Nurse to patient's ratio.

- Conflicts with patients.

- Conflicts with patient's family.

B-The Job Satisfaction scale: Kuopio University Hospital Job Satisfaction Scale (KUHJSS) 2008. ${ }^{[23]}$ It measures the general job satisfaction of the nursing staff. This scale has five domains: Personal factors, Work organization, Content and amount of work, Working unit and Leadership.

This questionnaire included 53 statements; each statement was rated on a 3 point Likert scale ranged from 1-3 points as following: Agree $=3$ point, Uncertain $=2$ point and Disagree $=1$ point).

The total scores of a structured interview schedule that assesses nurses' general job satisfaction of the nursing staff ranged from 52-156. It was categorized into three levels as the following:

- Dissatisfied (scored from 52-102);

- Average satisfaction (scored from 103-118);
- Satisfied (scored from 119-156).

Tool II: "Maslach Burnout Inventory Scale, prepared by Maslach, jackson and leiter (1996) ${ }^{[24]}$ has become the almost universally accepted gold tool to measure burnout and have high reliability and validity. The MBI is considered the goldmeasure for burnout and consists of three independently scaled measures.

The EE scale consists of nine items (1, 2, 3, 4, 5, 6, 7, 8 and 9) which measure feelings of being emotionally over extended and exhausted by one's profession. The DE have five items (10,11, 12, 13 and 14) consists of attitude of changes of individual when coming in contact with those who receive his/her services, as he/she begins to display a cold and impersonal contact with suffering. And finally, RPA has eight items $(15,16,17,18,19,20,21$ and 22) which measuring perception of the influence of others, wellbeing with work, as well as the relationship with problems; evidencing a feeling of dissatisfaction. The MBI has been widely validated and recognizes the different burnout patterns of individual s who may share common stressors.

The scale consists of 22 item self report surveys that use a 5-point Likert scale ranging from "does not happen at all" to almost on a daily basis . The average scores for each item range from 1.0 to 5.0. Respondents answered on five response categories to tick based on their feelings from "does not happen at all" to "almost on a daily basis" ("does not happen at all" = 1, Rarely happens (Less than five times a year) $=2$, Sometimes (From five to fifteen times per year) $=3$, Usually (more than fifteen times per year) $=4$, (almost on a daily basis $=5$ ). Accordingly, Items of one factor were grouped together and given a conceptual heading during the questionnaire development.

Burnout scoring: The maximum score of burnout scale 132. Burnout is conceptualized as continuous variable, ranging from low to average to high probability of experienced feeling of each element of burnout. A high degree of burnout is reflected in high scores on EE (maximum score of 45) and DE subscales (maximum score of 25) and in low scores on RPA subscale (maximum score 40). An average degree of burnout is reflected in average scores on the three subscales. A low degree of burnout is reflected in low scores on EE and DE subscales and in high scores on RPA subscale.

The total scores of burnout questions ranged from 22-110. It was categorized into three levels as the following:

- High: > 65\% (80-110);

- Moderate: 50\%-65\% (65-79);

- Low: <50\% (22-64).

*Higher scores of EE, DP and a lower score of PA 
indicate a higher level of burnout.

\subsection{Procedures}

- Official permission to conduct the study was obtained from Tanta university Hospital and Tanta Mental Health Hospital.

- Arabic translation of the tool I and II was done and tested for its translation.

- The study tools were tested for content validity by a jury composed of nine experts in psychiatric field (medicine and nursing).

- The study tools were tested and re-tested for reliability (alpha reliability $=0.7632)$.

- Before embarking in the actual study.

- A pilot study was carried out on 10 nurses, after taking a consent, to ascertain the clarity and applicability of the study tools and to identify obstacles that may be faced during data collection; these nurses were from psychiatric department in Tanta University Hospital and excluded from the study subjects. After its implementation and according to its results a necessary modification was done.

\subsection{Actual study}

Throughout the study process the following ethical points were considered:

(1) Participation in the study was voluntary and written informed consent was obtained from the studied nurses to participate in the study.

(2) Explanation the purpose of the study and emphasizing the right to withdraw at any point during the study.

(3) Assuring the nurses about their privacy and confidentiality of the obtained data.

(4) Orienting the participants about date, time and place of data collection.

(5) Orienting the participants that collected data will be used only for the purpose of scientific research.

Each participant was interviewed individually by using Tools I and II to assess the nurses' burnout syndrome and asked them to fill it in the presence of the researcher. The average time needed to complete the tools ranged between 20 to 30 minutes, scheduled as three days per week. The test took about three months.

\subsection{Statistical analysis}

The collected data were organized, tabulated and statistically analyzed using SPSS software (Statistical Package for the Social Sciences, version 19, SPSS Inc. Chicago, IL, USA).
For quantitative data, the range, mean and standard deviation were calculated. For qualitative data, which describe a categorical set of data by frequency, percentage or proportion of each category, comparison between two groups and more was done using Chi-square test $\left(\chi^{2}\right)$. For comparison between means of two groups of parametric data of independent samples, student $t$-test was used. For comparison between more than two means of parametric data, $F$ value of ANOVA test was calculated. Correlation between variables was evaluated using Pearson's correlation coefficient (r). Significance was adopted at $p<.05$ for interpretation of results of tests of significance.

\section{RESULT}

Table 1 shows characteristics of staff nurses in psychiatric department. It was observed that the highest frequency of nurses were female $(88.0 \%)$, more than half of staff nurses (52.0\%) aged more than 20-30 years. In relation to level of education, $48.0 \%$ and $32.0 \%$ were bachelors and diploma degree respectively. In relation to years of experience, the highest frequency of nurses was $76.0 \%$ staff nurses had experience $1-\geq 5$ years. More than half of them working 1-4 shifts per month $(52.9 \%)$ and $44 \%$ of them working more than 30 hours per week.

Table 2 and Figure 1 show the level of job satisfaction sub items among the studied psychiatric staff nurse's. It was observed that the majority (74.0\%) of staff nurses were dissatisfied with job compared to $12.0 \%$ had job satisfaction. In relation to job satisfaction sub items, it was found that the majority of nurses $(96.0 \%)$ were dissatisfied with leadership compared to none of them had satisfaction with leadership followed by $84.0 \%$ dissatisfied with work organization.

Table 3 and Figure 2 show level of burnout sub items among the studied psychiatric staff nurses. It was observed that the majority of nurses had high burnout $(44.0 \%)$ and $36.0 \%$ of them had low burnout compared to only $20.0 \%$ had moderate level of burnout. Regarding burnout sub items, specifically in relation to emotional exhaustion, it was found that $56.0 \%$ staff nurses experienced high level of emotional exhaustion compared to only $32.0 \%$ experienced low level of emotional exhaustion. It was noticed that study nurses had nearly the same level of depersonalization. As regard accomplishment, $64.0 \%$ staff nurses experienced low level of accomplishment while 16.0 experienced high level of accomplishment.

Table 4 and Figures $3 \& 4$ show the relationship and correlation between level of total burnout and total job satisfaction among the studied psychiatric staff nurses. Among nurses with low burn out, $44.4 \%$ were dissatisfied with their job compared to $90.9 \%$ of nurses of high burnout were dissatisfied. 
As regard satisfied nurses with their job, they represented $33.3 \%$ of those with low burnout compared to nothing among those of high burnout, with significant relationship $(p=.004)$. There was significance negative correlation between total burnout score and job satisfaction score (Significant correlation between increased burnout scores and dissatisfaction of nurses with their job) ( $p=.0001)$.

As shown in Table 5, total burnout and job satisfaction scores among the studied psychiatric staff nurses are in relation to their demographic and working data. In relation to total burnout scores, it was significantly related to; age (with highest score among those aged $40-<50$ ), number of working hours/week (with highest scores among working 20 hours and more), having working shifts (with highest scores for having shifts) and mean number of shifts/month (with highest scores for those working 7 shifts/month). In relation to total scores of job satisfaction, it was significantly related to; sex (with highest scores among male nurses), residence (with highest scores among those from rural areas) and mean number of shifts/month (with highest scores for those working 4 $-<7$ shifts/month).

Table 6 shows total burnout and job satisfaction scores among the studied psychiatric staff nurses are in relation to risk factors of burnout. In relation to total burnout scores, it was significantly related to; nurse-patient ratio (with highest score among those 1-3 ratio), types of conflict (with highest scores among verbal conflict), and think about moving from hospital or department to another because of work pressures: (with highest scores for agreeing to that). In relation to total scores of job satisfaction, it was significantly related to, nurse-patient ratio (with highest score among those 1-2 ratios), have another work outside hospital (with highest scores for having another work outside hospital).
Table 1. Demographic data of the studied psychiatric staff nurses $(n=51)$

\begin{tabular}{|c|c|c|}
\hline \multirow{2}{*}{ Variables } & \multicolumn{2}{|c|}{ The studied psychiatric staff nurses $(n=50)$} \\
\hline & n & $\%$ \\
\hline \multicolumn{3}{|l|}{-Age years: } \\
\hline $20-<30$ & 26 & 52.0 \\
\hline $30-<40$ & 12 & 24.0 \\
\hline $40-<50$ & 12 & 24.0 \\
\hline \multicolumn{3}{|l|}{ •Sex: } \\
\hline Male & 6 & 12.0 \\
\hline Female & 44 & 88.0 \\
\hline \multicolumn{3}{|l|}{ •Residence: } \\
\hline Urban & 22 & 44.0 \\
\hline Rural & 28 & 56.0 \\
\hline \multicolumn{3}{|c|}{ •Marital status: } \\
\hline Single & 14 & 28.0 \\
\hline Married & 10 & 20.0 \\
\hline Divorced & 26 & 52.0 \\
\hline \multicolumn{3}{|c|}{ •Have children: } \\
\hline Yes & 34 & 68.0 \\
\hline No & 16 & 32.0 \\
\hline \multicolumn{3}{|c|}{ •Education level: } \\
\hline Diploma & 16 & 32.0 \\
\hline Bachelor & 24 & 48.0 \\
\hline Practical & 10 & 20.0 \\
\hline \multicolumn{3}{|l|}{-Occupation: } \\
\hline Practical nurse & 36 & 72.0 \\
\hline Nurse leader & 14 & 28.0 \\
\hline \multicolumn{3}{|c|}{-Years of experience in the current department: } \\
\hline $1-<5$ & 38 & 76.0 \\
\hline $5-10$ & 12 & 24.0 \\
\hline \multicolumn{3}{|c|}{ •No. of working hours/week: } \\
\hline$<20$ & 18 & 36.0 \\
\hline $20-30$ & 10 & 20.0 \\
\hline$>30$ & 22 & 44.0 \\
\hline \multicolumn{3}{|c|}{ •Having working shifts: } \\
\hline Yes & 34 & 68.0 \\
\hline No & 16 & 32.0 \\
\hline \multicolumn{3}{|c|}{-If yes, what is the mean numbers per month: } \\
\hline $1-<4$ & 18 & 52.9 \\
\hline $4-<7$ & 12 & 35.3 \\
\hline$\geq 7$ & 4 & 11.8 \\
\hline
\end{tabular}

Table 2. Level of job satisfaction sub items among the studied psychiatric staff nurses $(n=50)$

\begin{tabular}{|c|c|c|c|c|c|c|}
\hline \multirow{3}{*}{$\begin{array}{l}\text { Job satisfaction sub items } \\
\text { (Each item scored 1-3) }\end{array}$} & \multicolumn{6}{|c|}{$\begin{array}{l}\text { Level of job satisfaction sub items among the studied psychiatric staff nurses } \\
(n=50)\end{array}$} \\
\hline & \multicolumn{2}{|c|}{ Dissatisfied (<50\%) } & \multicolumn{2}{|c|}{ Average satisfaction (50\%-65\%) } & \multicolumn{2}{|c|}{ Satisfied (> 65\%) } \\
\hline & $\mathbf{n}$ & $\%$ & $\mathbf{n}$ & $\%$ & $\mathbf{n}$ & $\%$ \\
\hline Leadership & 48 & 96.0 & 2 & 4.0 & 0 & 0 \\
\hline Work content and amount & 32 & 64.0 & 11 & 22.0 & 7 & 14.0 \\
\hline Work place & 36 & 72.0 & 12 & 24.0 & 2 & 4.0 \\
\hline Work Organization & 42 & 84.0 & 2 & 4.0 & 6 & 12.0 \\
\hline Personal factors & 18 & 36.0 & 16 & 32.0 & 16 & 32.0 \\
\hline Total job satisfaction & 37 & 74.0 & 7 & 14.0 & 6 & 12.0 \\
\hline
\end{tabular}




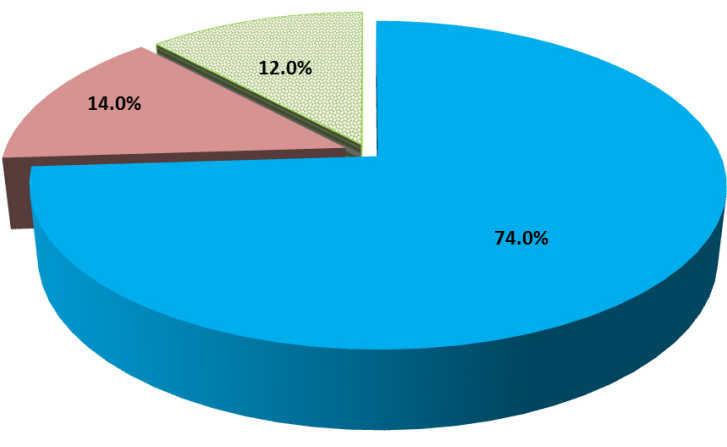

Dissatisfied Average satisfaction Satisfied

Figure 1. Level of total job satisfaction among the studied psychiatric staff nurses $(\mathrm{n}=50)$

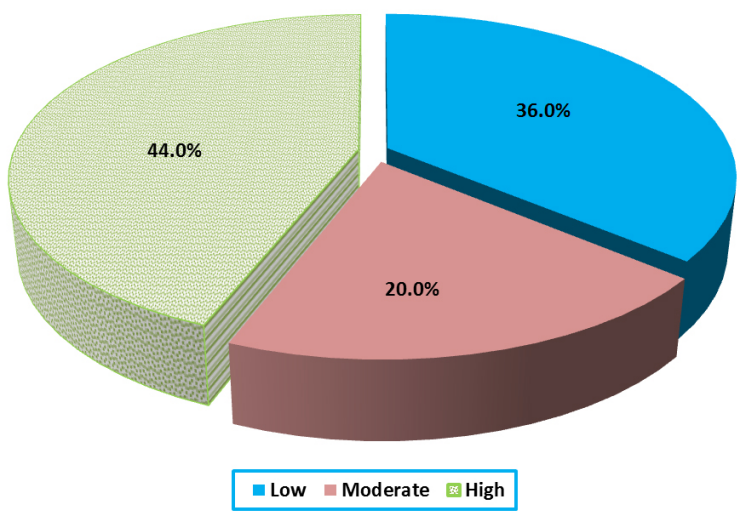

Figure 2. Level of total burnout among the studied psychiatric staff nurses $(n=50)$

Table 3. Level of burnout sub items among the studied psychiatric staff nurses $(n=50)$

\begin{tabular}{|c|c|c|c|c|c|c|}
\hline \multirow{3}{*}{$\begin{array}{l}\text { Burnout sub items } \\
\text { (Each item scored 1-5) }\end{array}$} & \multicolumn{6}{|c|}{ Level of burnout sub items among the studied psychiatric staff nurses $(n=50)$} \\
\hline & \multicolumn{2}{|c|}{ Low $(<50 \%)$} & \multicolumn{2}{|c|}{ Moderate (50\%-65\%) } & \multicolumn{2}{|c|}{ High (> 65\%) } \\
\hline & $\mathbf{n}$ & $\%$ & $\mathbf{n}$ & $\%$ & $\mathbf{n}$ & $\%$ \\
\hline Emotional Exhaustion & 16 & 32.0 & 6 & 12.0 & 28 & 56.0 \\
\hline Personal Accomplishment & 32 & 64.0 & 10 & 20.0 & 8 & 16.0 \\
\hline Depersonalization & 14 & 28.0 & 18 & 36.0 & 18 & 36.0 \\
\hline Optional items (fourth factor) & 10 & 20.0 & 12 & 24.0 & 28 & 56.0 \\
\hline Total burnout & 18 & 36.0 & 10 & 20.0 & 22 & 44.0 \\
\hline
\end{tabular}

Table 4. Relationship and correlation between level of total burnout and total job satisfaction among the studied psychiatric staff nurses $(\mathrm{n}=50)$

\begin{tabular}{|c|c|c|c|c|c|c|}
\hline \multirow{3}{*}{ Level of total job satisfaction } & \multicolumn{6}{|c|}{ Level of total burnout among the studied psychiatric staff nurses $(n=50)$} \\
\hline & \multicolumn{2}{|c|}{ Low $(\mathbf{n}=18)$} & \multicolumn{2}{|c|}{ Moderate (n = 10) } & \multicolumn{2}{|c|}{ High $(\mathrm{n}=22)$} \\
\hline & $\mathbf{n}$ & $\%$ & $\mathbf{n}$ & $\%$ & n & $\%$ \\
\hline Dissatisfied & 8 & 44.4 & 9 & 90.0 & 20 & 90.9 \\
\hline Average satisfaction & 4 & 22.2 & 1 & 10.0 & 2 & 9.1 \\
\hline Satisfied & 6 & 33.3 & 0 & 0 & 0 & 0 \\
\hline$\chi^{2} ; p$ & \multicolumn{6}{|c|}{$15.350 ; .004 *$} \\
\hline $\mathrm{r} ; p$ & \multicolumn{6}{|c|}{$-0.555 ; .0001 *$} \\
\hline
\end{tabular}

*Significant $(p<.05) \mathrm{r}=$ Correlation Coefficient

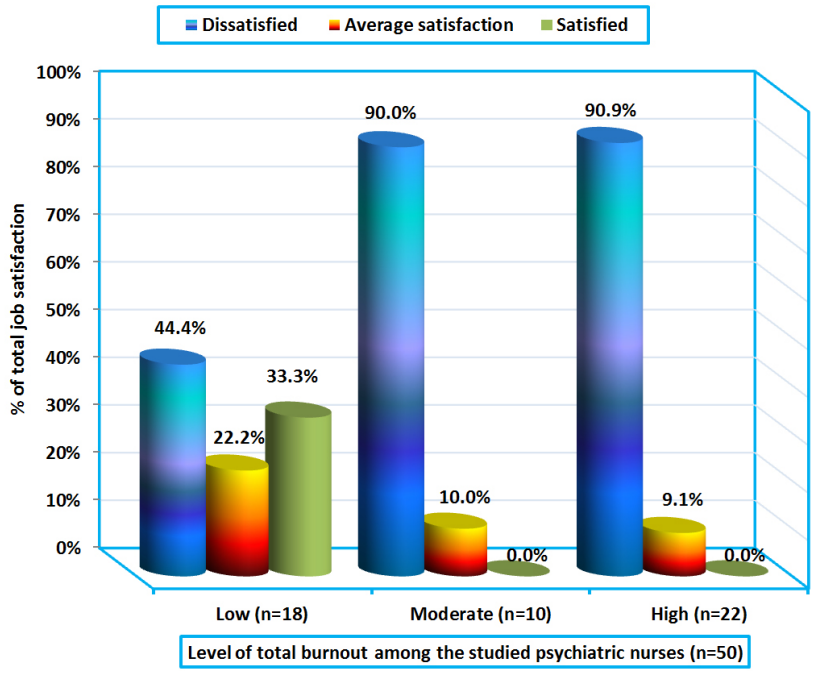

Figure 3. Relationship between level of total burnout and total job satisfaction among the studied psychiatric staff nurses $(\mathrm{n}=50)$

Published by Sciedu Press

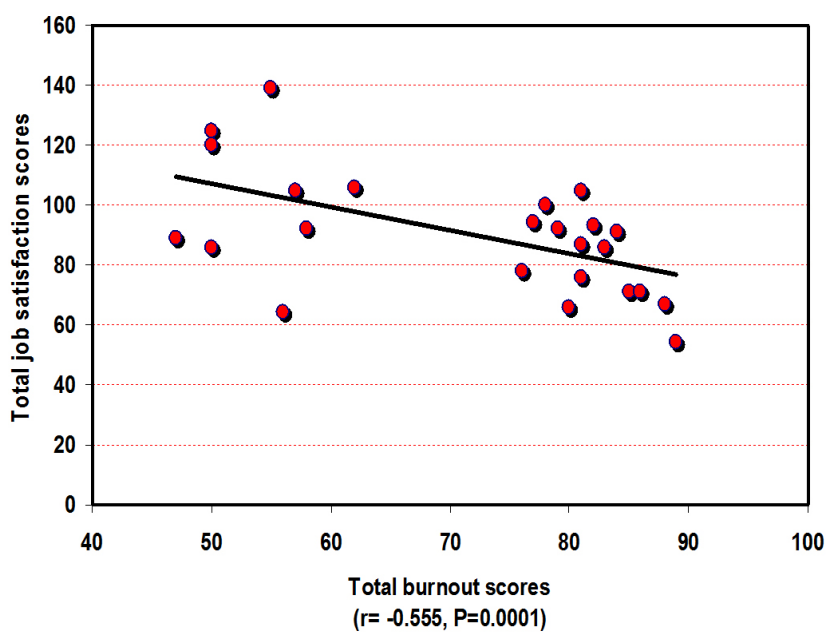

Figure 4. Correlation between level of total burnout and total job satisfaction among the studied psychiatric staff nurses $(\mathrm{n}=50)$ 
Table 5. Total burnout and job satisfaction scores among the studied psychiatric staff nurses in relation to their demographic and working data $(\mathrm{n}=50)$

\begin{tabular}{|c|c|c|c|c|c|c|}
\hline \multirow{3}{*}{ Demographic data } & \multicolumn{6}{|c|}{ Total scores of burnout and job satisfaction among the studied psychiatric staff nurses $(n=50)$} \\
\hline & \multirow{2}{*}{$\begin{array}{l}\text { Total burnout scores } \\
(22-110) \\
\text { Mean } \pm \text { SD } \\
\end{array}$} & \multirow{2}{*}{$\begin{array}{l}t \text {-test or } F \\
\text { value }\end{array}$} & \multirow[t]{2}{*}{$p$ value } & $\begin{array}{l}\text { Total job satisfaction } \\
\text { scores (51-153) }\end{array}$ & \multirow{2}{*}{$\begin{array}{l}t \text {-test or } F \\
\text { value }\end{array}$} & \multirow[t]{2}{*}{$p$ value } \\
\hline & & & & Mean \pm SD & & \\
\hline \multicolumn{7}{|l|}{-Age years: } \\
\hline $20-<30$ & $69.54 \pm 14.77$ & 3.840 & $0.029 *$ & $88.33 \pm 10.16$ & 1.842 & .170 \\
\hline $30-<40$ & $67.17 \pm 10.11$ & & & $99.33 \pm 24.22$ & & \\
\hline $40-<50$ & $80.83 \pm 2.52$ & & & $86.54 \pm 0.14$ & & \\
\hline \multicolumn{7}{|l|}{ •Sex: } \\
\hline Male & $71.67 \pm 12.94$ & 0.002 & 0.998 & $112.00 \pm 20.71$ & 3.157 & $.003 *$ \\
\hline Female & $71.68 \pm 14.39$ & & & $87.04 \pm 17.71$ & & \\
\hline \multicolumn{7}{|l|}{ •Residence: } \\
\hline Urban & $73.64 \pm 14.57$ & 0.867 & 0.390 & $83.64 \pm 14.78$ & 2.101 & $.041 *$ \\
\hline Rural & $70.14 \pm 13.79$ & & & $95.07 \pm 21.88$ & & \\
\hline \multicolumn{7}{|l|}{-Marital status: } \\
\hline Single & $65.71 \pm 14.99$ & 2.060 & 0.139 & $88.28 \pm 17.32$ & 1.084 & .347 \\
\hline Married & $76.60 \pm 14.63$ & & & $83.20 \pm 27.19$ & & \\
\hline Divorced & $73.00 \pm 12.82$ & & & $93.61 \pm 17.58$ & & \\
\hline \multicolumn{7}{|l|}{ •Education level: } \\
\hline Diploma & $69.87 \pm 17.09$ & 1.215 & 0.306 & $91.62 \pm 20.47$ & 0.077 & .926 \\
\hline Bachelor & $74.75 \pm 11.39$ & & & $89.08 \pm 12.89$ & & \\
\hline Practical & $67.20 \pm 14.53$ & & & $89.80 \pm 31.54$ & & \\
\hline \multicolumn{7}{|l|}{-Occupation: } \\
\hline Practical nurse & $69.72 \pm 14.61$ & 1.599 & 0.116 & $90.22 \pm 2154$ & 0.104 & .918 \\
\hline Nurse leader & $76.71 \pm 11.71$ & & & $89.57 \pm 14.89$ & & \\
\hline \multicolumn{7}{|c|}{-Years of experience in the current department: } \\
\hline $1-<5$ & $72.13 \pm 13.88$ & 0.399 & 0.691 & $89.29 \pm 20.28$ & 0.474 & .637 \\
\hline $5-10$ & $70.25 \pm 15.31$ & & & $92.42 \pm 18.62$ & & \\
\hline \multicolumn{7}{|c|}{ •No. of working hours/week: } \\
\hline$<20$ & $67.22 \pm 14.66$ & 3.534 & $0.037^{*}$ & $93.22 \pm 21.62$ & 2.552 & .089 \\
\hline $20-30$ & $81.20 \pm 5.27$ & & & $77.80 \pm 15.47$ & & \\
\hline$>30$ & $71.00 \pm 14.75$ & & & $93.00 \pm 18.45$ & & \\
\hline \multicolumn{7}{|c|}{ •Having working shifts: } \\
\hline Yes & $74.97 \pm 12.81$ & 2.535 & $0.015 *$ & $87.91 \pm 18.58$ & 1.113 & .271 \\
\hline No & $64.69 \pm 14.56$ & & & $94.56 \pm 21.99$ & & \\
\hline \multicolumn{7}{|c|}{-If yes, what is the mean numbers per month: } \\
\hline $1-<4$ & $78.05 \pm 12.93$ & 3.305 & $0.042 *$ & $78.05 \pm 12.93$ & 6.193 & $.005 *$ \\
\hline $4-<7$ & $68.00 \pm 12.13$ & & & $100.83 \pm 19.87$ & & \\
\hline$\geq 7$ & $82.00 \pm 1.15$ & & & $86.50 \pm 0.58$ & & \\
\hline
\end{tabular}

Note. Data are presented as mean \pm SD; *Significant $(p<.05)$

\section{Discussion}

Psychiatric nurses are misunderstood in addition to social bias because of the nature of their work. Their profession includes responding to emergencies and the psychological strain of the threat of aggression from patients. Thus, such nurses experience occupational burnout. Burnout is syndrome common between psychiatric nurses that can lead to depression, low job satisfaction, and lack of empathy 
towards patients, diminished job performance, increased in- relation between burnout and job satisfaction among psychiterpersonal difficulties, family dysfunction, and consequently atric nurses.

affect the patients care. ${ }^{[25]}$ So, study conducted to assess the

Table 6. Total burnout and job satisfaction scores among the studied psychiatric staff nurses in relation to risk factors of burnout $(\mathrm{n}=50)$

\begin{tabular}{|c|c|c|c|c|c|c|}
\hline \multirow[b]{2}{*}{ Risk factors of burnout } & \multicolumn{6}{|c|}{ Total scores of burnout and job satisfaction among the studied psychiatric staff nurses $(n=50)$} \\
\hline & Total burnout scores & $\begin{array}{l}t \text {-test or } \\
\text { F value }\end{array}$ & $p$ value & $\begin{array}{l}\text { Total job } \\
\text { satisfaction scores }\end{array}$ & $\begin{array}{l}t \text {-test or } \\
\text { F value }\end{array}$ & $p$ value \\
\hline \multicolumn{7}{|l|}{-Nurse to patient's ratio: } \\
\hline $1: 1$ & $70.57 \pm 13.71$ & 3.577 & $.021 *$ & $95.43 \pm 14.94$ & 4.274 & $.010^{*}$ \\
\hline $1: 2$ & $57.67 \pm 3.39$ & & & $103.00 \pm 33.62$ & & \\
\hline $1: 3$ & $77.30 \pm 13.61$ & & & $79.20 \pm 16.18$ & & \\
\hline$>1: 4$ & $70.40 \pm 14.46$ & & & $96.40 \pm 12.59$ & & \\
\hline Once per day & $77.50 \pm 1.73$ & & & $85.00 \pm 8.08$ & & \\
\hline More than above & $71.00 \pm 5.01$ & & & $91.50 \pm 0.58$ & & \\
\hline \multicolumn{7}{|l|}{-Conflicts with: } \\
\hline Colleagues & $72.83 \pm 17.91$ & 0.064 & .939 & $90.33 \pm 27.10$ & 0.422 & .658 \\
\hline Relatives of patients & $71.32 \pm 13.53$ & & & $90.87 \pm 19.40$ & & \\
\hline Patients & $73.50 \pm 18.06$ & & & $81.25 \pm 12.01$ & & \\
\hline \multicolumn{7}{|l|}{-Types of conflicts: } \\
\hline Physical & $61.00 \pm 12.68$ & 11.132 & $.0001 *$ & $94.33 \pm 27.28$ & 1.205 & .309 \\
\hline Verbal & $75.45 \pm 12.20$ & & & $88.10 \pm 18.48$ & & \\
\hline Sexual & $50.00 \pm 0.00$ & & & $103.00 \pm 19.63$ & & \\
\hline \multicolumn{7}{|c|}{-Have another work outside hospital: } \\
\hline Yes & $66.67 \pm 11.32$ & 0.927 & .359 & $105.33 \pm 0.52$ & 2.090 & $.042 *$ \\
\hline No & $72.36 \pm 14.41$ & & & $87.95 \pm 20.19$ & & \\
\hline No & $67.00 \pm 14.70$ & & & $106.87 \pm 18.64$ & & \\
\hline \multicolumn{7}{|c|}{-Health deterioration due to work pressure: } \\
\hline Yes & $73.00 \pm 14.18$ & 0.176 & .861 & $81.86 \pm 17.79$ & 3.788 & $.0001 *$ \\
\hline No & $72.30 \pm 12.65$ & & & $101.60 \pm 17.82$ & & \\
\hline
\end{tabular}

*Significant $(p<.05)$

In relation to the total staff nurses' job satisfaction, it was found that the majority of nurses had job dissatisfaction and the difference was significant. Regarding job satisfaction components, majority of staff nurses were dissatisfied with leadership and organization. This study results are congruent with previous study reported that nurses were found to be dissatisfied with their work, they expressed issues such as lack of autonomy, undervalue by the medical staff personnel and nursing managers, decrease opportunities for professional development, lack of recognition and low morale. Nurse's level of job satisfaction assessed on psychiatric nurses in a psychiatric unit revealed that there was a feeling of lack of teamwork between peers as well as amongst the multidisciplinary team. ${ }^{[26]}$ In the same line, Aronson (2004) conducted a study in psychiatric hospitals who examined the level of job satisfaction among nurses. Nurses reported low levels of job satisfaction. Also, high levels of burnout among mental health nurses resulted in lower job satisfaction. ${ }^{[27]}$
In relation to staff 'nurses' burnout and its components. It was observed that the majority of nurses had high burnout. Regarding burnout components, in relation to emotional exhaustion, it was found that the majority of nurse's have high emotional exhaustion and depersonalization compared to low accomplishment. This congruent with a study done by Zaki (2016) showed that psychiatric nurses are suffering from job burnout, majority of the psychiatric nurses did not have the psychiatric nursing ability, not have knowledge about the laws, the institutions other than the policies that are important to nursing. The researcher explained that this could be related to psychiatric nurses' lack of preparation and proficiencies in dealing with psychiatric patients which has enforced stress on the nurse's work and loses the ability to do their job perfectly. ${ }^{[28]}$

These results are different with studies of Ogresta et al. $(2008)^{[29]}$ and Sherring \& Knight (2009) ${ }^{[30]}$ in which burnout 
levels were moderate; while in Australia, levels of burnout were low. High burnout levels among psychiatric nurses were illustrated by a poor work environment through low social support from supervisors and colleagues. High burnout levels also might be because of dealing with uncooperative patients with prolonged prognosis, which cause helplessness and emotional exhaustion.

Regarding association between work-related factors and job satisfaction, in relation to working hours, it was found that more than half of them were dissatisfied who working 20 30 hours per week and the difference was significant while half of them dissatisfied who working more than 7 shifts per month. Regarding nurse to patient ratio, it was found the majority of dissatisfied nurses were among 1-4 ratios and more, the difference was significant. Also, it was found that majority of nurses had low level of satisfaction were thinking about leaving job due to work pressures and the difference was significant. Also, it was found more than half of dissatisfied nurses had Health deterioration due to work pressure. That is similar to study In Saudi Arabia, a positive relation were found between years of experience and job satisfaction. Age and years of experience are related study variables; young nurses and less working experience are more having job dissatisfaction. Psychiatric nurses, especially the young nurses who not yet developed defensive mechanisms were frustrated in their attempt to improve patients' quality of life. ${ }^{[31]}$

In relation to association between work - related factors and burnout. In relation to years of experience, it was observed that the highest frequency of nurses had high level of burnout were among $1-5$ years of experience although the difference was not significant. It was found the majority of them had high level of burnout that working more than 7 shifts per month, and the difference was significant. Regarding nurse to patient ratio, it was found half of nurses had high level of burnout were among 1-4 ratios and the difference was significant. Also, it was found that majority of nurses that had high level of burnout were thinking about leaving job due to work pressures and the difference was significant. Also, It was found the majority of nurses who had high level of burnout had Health deterioration due to work pressure. This similar to a previous study reported that Caseload size (nurse to patient ratio) was found to predict high emotional exhaustion and reduced personal accomplishment. Nurses in hospitals with the highest caseloads are more experienced job burnout. ${ }^{[32]}$

This is in agreement with previous studies that found that burnout levels were higher among inexperienced nurses. In this study, they also found that nurses with 6-10 years' expe- rience have higher overall job burnout than nurses with less than 5 years or more than 11 years' experience. This result is similar to the results in which middle generation nurse (those with 6-10 years' experience) are given more work loads, and multiple roles during this stage that explain why mid-generation nurses experience burnout more often. Even more, it was found that more job experience is related to greater satisfaction. Greater work experience allow for more accomplishments and greater organizational commitment, which are protective factors against job burnout. ${ }^{[33]}$

In the present study, concerning relation between staff nurses' burnout and job satisfaction. It was found that there was significance negative relation between burnout and job satisfaction, the highest frequency of nurses had high burnout had low level of job satisfaction. These findings are come in agreement with previous study; Iranian nurses also had perceived work dissatisfaction and health threats. Psychiatric nurses in Iran experienced a significantly greater degree of emotional exhaustion and job dissatisfaction than medical nurses. Significant positive correlation was found between ages, years of experience, and emotional exhaustion of the psychiatric nurses. ${ }^{[34]}$

In the same line previous study found that psychiatric nurses had more burnout and dissatisfaction about their job because of: 'stigma of mental illness, 'over work-load leading to cognitive loading', 'psychopathology and behavioral disorders, e.g., high degree of aggressiveness, suicidality, and persecution' ${ }^{[35]}$

In the contrary it was found that the general nurses had more burnout than the psychiatric nursing. These results are new when compared to previous studies that reported that psychiatric nurses had a high risk for burnout syndrome and dissatisfaction with their nursing jobs. An acceptable explanation of the high burnout among general nurses in this study was because of the psychiatric nurses were received high pay packages and benefits than the general nurses having the pay and other benefits are much less. ${ }^{[36]}$

Other study findings also found a relation between job satisfaction and burnout. Findings revealed that job satisfaction is significantly correlated with burnout by emotional exhaustion, depersonalization, and personal accomplishment. Result of the present study is in parallel to the study by Dolan that relation between job satisfaction and burnout. Result revealed that the higher job satisfaction, the lesser risk of nurses' burnout. This result was similar to a study by Roussel, Russell and Swansburg found that job satisfaction may reduce burnout. Moreover, result suggests that high job satisfaction decreases the nurses' burnout. ${ }^{[37]}$ 
This finding in the same line of the study of Ulmer, ${ }^{[38]}$ which revealed that, satisfied nurses are more productive and committed. Therefore, a highly satisfied and free from burnout nurses' will provide a quality of care and patient care satisfaction. In conclusion, findings of this study will help the nurse to avoid aggravating their burnout, and developing strategies to enhance job satisfaction, and maintaining a quality nursing care to the patients.

Thus, novel strategies to prevent and manage nurses' burnout. Furthermore, enrichment programs to job satisfaction and burnout. The results of study can provide references for psychiatric nurses in understanding their perceptions of stress, as well as positive and healthy coping strategies to prevent job burnout and enhancement of psychiatric nursing care quality.

\section{Conclusion}

It can be concluded that the majority of nurses had job dissatisfaction and high burnout specifically, in relation to emotional exhaustion; it was found that the majority of nurses had high emotional exhaustion and depersonalization in comparison with low accomplishment. It was found that there was significance negative relation between burnout and job satisfaction, the highest frequency of nurses had high burnout had low level of job satisfaction.

\subsection{Recommendations}

Based on the results of the study, the following recommendations are suggested:

\subsubsection{Reduce burnout in nursing practice}

(1) Healthy working environment and improvement in work organization to increase job satisfaction and maintain the nurses' motivation and productivity.

(2) A comprehensive individual and organizational. Interventional approach to minimize the risk of burnout among mental health nurses.

(3) Therapeutic programs to enhance positive mental health in psychiatric nurses such as emotional maturity, locus of control, general well-being, and adjustment.

(4) Early discovery of burnout syndrome could contribute to fostering more work efficiency and better health care for patients.

(5) The results of our study can provide references for psychiatric nurses to assist them in understanding their perceptions of stress, as well as provide them with positive and healthy coping strategies to prevent burnout syndrome and promote psychiatric nursing care quality.

(6) Continuous workshops for understanding the stressors that have an impact on psychiatric nurses will help to raise the stress bearing capacity among psychiatric nurses.

\subsubsection{Job satisfaction}

- Enhancement and appreciating good performance.

- Challengeable abilities activities to remain the nurse active all the times.

- Encouraging team work spirit among nurses.

- Improving interpersonal relationship among leadership managers and nurses.

- Safe and secure hospital environment.

- Workload management by proper planning of duty schedule, recruitment of qualified nurses and also by nursing training to plan their priorities.

\subsubsection{Nursing education}

- Stress management, assertiveness, and more knowledge base help the nurses to work independently in clinical field.

- Stress management program and coping strategies can be included in nursing education to manage their own stress in future.

\subsubsection{Nursing research}

Scientific updated researches on burnout and job satisfaction which need continuous monitoring and evaluation.

\section{Conflicts of InTEREST Disclosure}

The author declares that there is no conflict of interest statement.

\section{REFERENCES}

[1] Maslach C, Schaufeli W, Leiter M. Job burnout. Annual Review of Psychology. 2001; 52: 397-422. PMid:11148311 https://doi.or g/10.1146/annurev.psych.52.1.397

[2] Patrick K, Lavery J. Burnout in nursing. Australian Journal of Advanced Nursing. 2007; 24(3): 43-8.

[3] Jennings BM. Work Stress and Burnout Among Nurses: Role of the Work Environment and Working Conditions Agency for Healthcare
Research and Quality, Chapter 26, 2008.

[4] Matin HZ, Kalali NS, Reza M, et al. Do demographic variables moderate the relationship between job burnout and its consequences? Iranian Journal of Management Studies. 2012; 5(1): 47-62.

[5] Gemlike N, Sisman FA, Sigri U. The relationship between burnout and organizational commitment among health sector staff in Turkey. Journal of Global Strategic Management. 2010.

[6] Freudenberger HJ. Staff burn-out. Journal of Social Issues. 1974; 
30(1): 159-65. https://doi.org/10.1111/j.1540-4560.19 74.tb00706.x

[7] Maslach C, Schaufeli WB, Leiter MP. Job burnout. Annual Review of Psychology. 2011; 53: 397-422. PMid:11148311 https: //doi.org/10.1146/annurev.psych.52.1.397

[8] Poncet MC, Toullic P, Papazian L, et al. Burnout syndrome in critical care nursing staff. American Journal of Respiratory and Critical Care Medicine. 2007; 175(7): 698-704. PMid:17110646 https://doi.org/10.1164/rccm.200606-8060C

[9] Duquette A, Kerouac S, Sandhu BS, et al. Psychosocial determinants of burnout in geriatric nursing. International Journal Nursing Studies. 1975; 32(5): 443-56. https ://doi .org/10.1016/0020-748 9 (95) 00006-J

[10] Sveinsdottir H, Biering P, Ramel A. Occupational stress, job satisfaction, and working environment among Icelandic nurses: A crosssectional questionnaire survey. International Journal of Nursing Studies. 2006; 43(7): 875-89. PMid:16360157 https ://doi .org/10 $.1016 / j$.ijnurstu.2005.11.002

[11] Lambert VA, Lambert CE. Nurses' workplace stressors and coping strategies. Indian Journal of Palliative Care. 2008; 14(1): 38-44. https://doi.org/10.4103/0973-1075.41934

[12] Sundin L, Hochwa J, Bildt C, et al. The relationship between different work-related sources of social support and burnout among registered and assistant nurses in Sweden: A questionnaire survey. International Journal of Nursing Studies. 2007; 44(5): 758-69. PMid:16530200 https://doi.org/10.1016/j.ijnurstu.2006.01.004

[13] Aiken LH, Clarke S, Sloane DM, et al. Importance of work environments on hospital outcomes in nine countries. International Journal for Quality in Health Care. 2011; 23(4): 357-64. PMid:21561979 https://doi.org/10.1093/intqhc/mzr022

[14] Maslach C, Schaufeli WB, Leiter MP. Job burnout. Annual Review of Psychology. 2001; 53: 397-422. PMid:11148311 https: //doi.org/10.1146/annurev.psych.52.1.397

[15] Fagin L, Brown D, Bartlett H, et al. The Claybury community psychiatric nurse stress study: Is it more stressful to work in hospital or the community? Journal of Advanced Nursing. 2008; 22(2): 347-56. PMid:7593957 https://doi.org/10.1046/j.1365-2 $648.1995 .22020347 . x$

[16] Adali E, Priami M, Evagelou H, et al. Alevizopoulos. Burnout in psychiatric nursing personnel in Greek hospitals. The European Journal of Psychiatry. 2003; 17(3): 173-11.

[17] Price J. Reflections on the determinants of voluntary turnover. International Journal of Manpower. 2001; 22(7): 600-24. https ://doi . or g/10.1108/EUM0000000006233

[18] Lu H, While A, Barriball K. Job satisfaction among nurses: A literature review. International Journal of Nursing Studies. 2005; 42: 211-27. PMid:15680619 https://doi.org/10.1016/j.ijnurs tu.2004.09.003

[19] Nizami A, Rafique I, Aslma F, et al. occupational stress and job satisfaction among nurses at tertiary care hospital. JPSS. 2012; 3(1)

[20] William A. Job stress, job satisfaction and intent to leave employment among maternal and child health nurses. (Unpublished dissertation). West Virginia; Marshall University; 2003.

[21] Shinde MB, Durgawale PM. Nursing Audit of Health Workers Providing Health Services in Rural Area with Special Emphasis to Community Satisfaction in Satara District. International Journal of Science and Research (IJSR). 2014; 3(2): 94-104.

[22] Rosales RA, Labrague LJ, Rosales GL. Nurses job satisfaction and burnout: is there a connection. Int J Adv Nsg stud. 2013; 2(1): 10 . https://doi.org/10.14419/ijans.v2i1.583
[23] Utriainen K, KyngÄs H. Hospital nurses' job satisfaction: a literature review. Journal of Nursing Management. 2009; 17(8): 1002-10. PMid:19941574 https://doi .org/10.1111/j.1365-2834.20 09.01028.x

[24] Maslach C, Jackson SE, Schwab RL. Maslach Burnout InventoryEducators Survey (MBI-ES). In C. Maslach, S. E. Jackson, \& M P. Leiter (Eds.), MBI Manual. 3rd ed. Palo Alto, CA: Consulting Psychologists Press; 1996.

[25] Shih EC, Hou WL, Lin PL. Personal Characteristics, Workplace Stressors, and Occupational Burnout among Psychiatric Nurses in Southern Taiwan- A Cross-sectional Study. Nursing and Health Journal. 2016; 4(2): 15-23. https://doi.org/10.13189/nh.2016 .040201

[26] Kilfedder CJ, Kevin PG, Tony J. Burnout in psychiatric nursing. Journal of Advanced Nursing. 2001; 34(3): 383-96. PMid:11328444 https://doi .org/10.1046/j.1365-2648.2001.01769.x

[27] Shaher H. Hamaideh. Burnout, Social Support, and Job Satisfaction among Jordanian Mental Health Nurses. Issues in Mental Health Nursing. 2011; 32: 234-42. PMid:21355758 https ://doi .org/10 $.3109 / 01612840.2010 .546494$

[28] Zaki R. Job Stress and Self- Efficacy among Psychiatric Nursing Working in Mental Health Hospitals at Cairo. Journal of Education and Practice. 2016; 7(20): 103-13.

[29] Ogresta J, Rusac S, Zorec L. Relation between burnout syndrome. Croatian Medical Journal. 2008; 49: 364-74. PMid:18581615 https : //doi.org/10.3325/cmj.2008.3.364

[30] Sherring S, Knight D. An exploration of burnout among city mental health nurses. British Journal of Nursing. 2009; 18(20): 1234 1240. PMid:20081659 https://doi.org/10.12968/bjon. 2009 .18 .20 .45114

[31] Al-Ahmadi H. Factors affecting performance of hospital nurses in Riyadh Region, Saudi Arabia. International Journal of Health Care. 2009; 22(1): 40-54. PMid:19284170 https://doi.org/10.110 $8 / 09526860910927943$

[32] Aiken L, Clarke S, Sloane D, et al. Hospital nurse staffing and patient mortality, nurses burnout, and job dissatisfaction. Journal of the American Medical Association. 2002; 288(16): 1987-1993. PMid:12387650 https://doi.org/10.1001/jama.288.16.19 87

[33] Wu XL, Cai WX, Hsu CH. The Study of Occupational Burnout of Nursing Staff to Leisure Coping Strategies. Leisure Industry Research. 2010; 8(3): 145-167.

[34] Lagerström M, Josephson M, Arsalani N, et al. Striving for balance between family and work demands among Iranian nurses. Nurs Sci Q. 2010; 23: 166-72. PMid:20378918 https://doi.org/10.117 7/0894318410362543

[35] Dickinson T, Wright KM. Stress and burn-out in forensic mental health nursing: A literature review. British Journal of Nursing. 2008; 17(2): 82-7. PMid:18414278 https://doi.org/10.12968/bjon. 2008.17 .2 .28133

[36] Mathew J, Ram D, Bhattacharjee D, et al. Self-Esteem, Job Satisfaction and Burnout between General and Psychiatric Nursing Staff: A Comparative Study. Journal of Health Management. 2013; 15(4): 595-612. https://doi .org/10.1177/0972063413516232

[37] Rheajane A, Rosales LJ, Labrague GL. Nurses' Job satisfaction and Burnout: Is there a connection? International Journal of Advanced Nursing Studies. 2013; 2(1): 1-10. https://doi.org/10.14419 /ijans.v2i1.583

[38] Ulmer D, Syptak JM, Marsland DW. Job satisfaction: Putting Theory in practice. American Academy of family physicians. 2008. Available from: http://www . aafp.org/fpm/aairoomfm/26.htmp 